Research Square
Preprints are preliminary reports that have not undergone peer review.

They should not be considered conclusive, used to inform clinical practice, or referenced by the media as validated information.

\title{
Case-control Study on p73 rs1801173 C > T Gene Polymorphism and Susceptibility to Gastric Cancer in a Chinese Han Population
}

Xuyu Gu ( $\sim$ gu1806@126.com)

Southeast University

Xiaoyan Wang

Suqian First People's Hospital

Huiwen Pan

Jiangsu University

Zhenjun Gao

Fudan University

Guowen Ding

Jiangsu University

Yu Fan

Jiangsu University

Research article

Keywords: Gastric Cancer, Single Nucleotide Polymorphism, p73, rs1801173

Posted Date: December 8th, 2020

DOI: https://doi.org/10.21203/rs.3.rs-120606/v1

License: (c) (i) This work is licensed under a Creative Commons Attribution 4.0 International License. Read Full License 


\section{Abstract}

Objective: This study aimed to investigate the association between $p 73 \mathrm{C} 14 \mathrm{~T}$ (rs1801173) polymorphism and the risk of GC in a Chinese Han population.

Methods: A hospital-based case-control study was conducted. A total of $577 \mathrm{GC}$ cases and 678 normal controls were recruited. Their genotypes were determined using the Snapshot method.

Results: The genotype frequency distribution of the case group and the control group were consistent with the Hardy-Weinberg equilibrium. No significant difference was found in the distribution of gender, age, and drinking history between the case group and the control group. A correlation was observed between smoking and the incidence of GC $(P=0.006)$. Three genotypes of $\mathrm{CC}, \mathrm{CT}$, and TT were found in the rs1801173 locus of $p 73$. The distribution of the dominant model/recessive model did not significantly differ $(P=0.688 ; 0.937)$. No statistical difference was found even after adjustment was performed via logistic regression analysis $(P=0.703 ; 0.990)$. The frequency distribution between the two groups also did not significantly differ $(P=0.763)$.

Conclusion: Smoking is related to the occurrence and development of GC. No association was found between $p 73$ rs $1801173 \mathrm{C}>\mathrm{T}$ SNP and the risk of GC in a Chinese Han population. However, additional larger studies and tissue-specific biological characterization are required to confirm these findings.

\section{Introduction}

Gastric cancer (GC) is one of the most common malignant tumors, ranking third in the number of cancer deaths worldwide ${ }^{[1]}$. The latest statistics from the Chinese National Cancer Center from a report in February 2018 showed that although the overall incidence of GC is declining, it still remains second in terms of incidence among all malignancies in China, just below lung cancer ${ }^{[2]}$. Despite remarkable progress, the current treatments for GC remain inefficacious, with overall 5 -year survival rates $<30 \%$. At the time of diagnosis, most patients have been diagnosed with advanced cancer and metastasis ${ }^{[3]}$. GC invasion and metastasis are complex processes involving multiple factors. Increasing evidence has proven that environmental and genetic factors contribute to the occurrence and development of GC. In addition to environmental risk factors, such as diet and HP infection, single nucleotide polymorphism (SNP) may play an important role in GC cancerization as a genetic factor. SNPs are polymorphisms in DNA sequences caused by mutations in the genome's single nucleotides. They are the most common form of human genetic variation, accounting for $>90 \%$ of all known morphologies ${ }^{[4]}$. Understanding the underlying mechanisms of GC initiation and progression may promote biomarker development for early detection of cancer. Previous epidemiological studies found increasing numbers of genetic variations that influence GC susceptibility ${ }^{[5]}$. However, the association of the polymorphisms in the genes and GC susceptibility remains largely unknown. Hua et al. found that genetic variations in LIG3 may play a weak role in modifying the risk of GC ${ }^{[6]}$. He et al. systematically analyzed the associations between nine polymorphisms in four key genes (XPA, ERCC1, ERCC2, and ERCC4) in the nucleotide excision repair pathway and the risk of GC in a Chinese population. They concluded that the ERCC1 polymorphisms may affect the risk of GC in the Chinese Han population ${ }^{[7]}$. They also studied the genetic variations of $m T O R C 1$ and risk of GC in an Eastern Chinese population and found that the functional polymorphisms of $m T O R$ may contribute to the risk of $\mathrm{GC}^{[8]}$. In 2004, the authors of the present study found that $p 73 \mathrm{rs} 1801173 \mathrm{C}>$ T polymorphisms are associated with an increased risk of esophageal cancer in a Chinese population ${ }^{[0]}$.

Tumor protein p73 (TP73), also known as p53-like transcription factor, is a pivotal member of the $p 53$ (TP53) family, which affects cell proliferation, apoptosis, and cell-cycle regulation. $p 73$ is located at $1 p 36.33$, mapping to a region that is often deleted in cancers ${ }^{[10]}$. $p 73$ activates the transcription of $p 53$-responsive genes, which participate in cell-cycle control, DNA repair, and apoptosis and inhibits cell growth in a p53-like manner by inducing apoptosis or G1 cell-cycle arrest ${ }^{[11]}$. Thus, $p 73$ has tumor-suppressor functions. $p 73$ has some significant differences from $p 53$. In contrast to $p 53$-deficient mice, those lacking $p 73$ show no increased susceptibility to spontaneous tumorigenesis ${ }^{[12]}$.

At least 19 polymorphisms have been recognized in $p 73$ at present. Ten polymorphisms are in the exon region, eight are in the intron region, and one is in the region of gene promoter. However, the functionality of most of these polymorphisms has not been recognized yet ${ }^{[13]}$. The $1 \mathrm{p} 36.3$ region, where $\mathrm{p} 73$ is coded, is deleted in different malignancies via loss of heterogeneity. Although $p 73$ mutation is rare and occurs in less than $2 \%$ of all cancers, the lack of heterogeneity in locus p73 is common in a variable rate in different cancers ${ }^{[14]}$. As a result, the genetic changes in $p 73$ are critical in malignancies ${ }^{[15]}$. Two related SNPs in regions $4(\mathrm{G}>\mathrm{A})$ and $14(\mathrm{C}>\mathrm{T})$ of exon 2 in $p 73$ resulted in the formation of a stem-loop structure that could affect the gene function via changes in its expression. Molecular epidemiology studies have indicated an association between this polymorphism and the risk of cancers in human; however, the results were inconsistent ${ }^{[16]}$.

Previous research demonstrated that $p 73$ gene polymorphisms are related to the occurrence of various cancers, including esophageal cancer ${ }^{[17]}$, rectal cancer $^{[18]}$, breast cancer ${ }^{[19]}$, lung cancer ${ }^{[20]}$, and cervical cancer ${ }^{[21]}$. However, no research could be found on $p 73$ gene polymorphism and GC susceptibility. This study aimed to investigate the relation between C14T polymorphism in $p 73$ and the risk of GC in a Chinese Han population.

\section{Ethical approval of the study protoco}

This study complied with the World Medical Association Declaration of Helsinki in terms of ethical conduct of research involving human subjects and/or animals and received approval from the Review Board of Jiangsu University (Zhenjiang, China). Written informed consent was provided by all the subjects in this study.

\section{Materials And Methods}


Between May 2013 and June 2017, 577 subjects with GC were recruited consecutively at the Affiliated People's Hospital of Jiangsu University (Zhenjiang, China). Their average age of the case group was $61.34 \pm 11.097$ years, with 394 males and 183 females. All cases were pathologically diagnosed as GC. The exclusion criteria were as follows: patients who previously had cancer and those with any metastasized cancer and undergoing radiotherapy or chemotherapy. As controls, 678 patients without cancer were matched to the cases in terms of age ( \pm 5 years) and sex. Their average age was $62.31 \pm 7.549$ years, with 456 males and 222 females. The controls were recruited from the abovementioned hospital during the same time period. Both groups are Chinese Han people, and they are not related by blood. Moreover, We had access to information that could identify individual participants during or after data collection.

Using a pre-tested questionnaire, trained interviewers questioned each subject personally and obtained demographic data information (e.g., age and sex) and related risk factors (such as tobacco smoking and alcohol consumption). Venous blood samples ( $2 \mathrm{~mL}$ ) were collected after each interview. The definition of "smokers" was smoking one cigarette per day for $>1$ year. The definition of "alcohol drinkers" was consumption of $\geq$ three alcoholic drinks a week for $>$ 6 months.

Blood samples were collected from patients by using vacutainers and transferred to tubes lined with ethylenediamine tetra-acetic acid. Genomic DNA was isolated from whole blood by using a QIAamp DNA Blood Mini Kit (Qiagen, Berlin, Germany). Sample DNA was amplified via PCR in accordance with the manufacturer's recommendations. The samples were genotyped using the SnapShot method, with technical support from Shanghai Biowing Applied Biotechnology Co. as previously described. For quality control, repeated analyses were performed on 160 (12.17\%) randomly selected samples with high DNA quality.

\section{Statistical analyses}

The distributions of demographic characteristics, selected variables, and genotypes of the $p 73$ variant differences between the cases and controls were evaluated using the $\chi 2$ test. Logistic regression analyses was used to estimate the associations between the SNPs and the risk of GC for crude and adjusted ORs when adjusting for age, sex, smoking, and drinking status. The Bonferroni correction procedure was also applied because of the number of comparisons. The Hardy-Weinberg equilibrium (HWE) was tested using the goodness-of-fit $\chi^{2}$ test to compare the observed genotype frequencies to the expected ones among the controls. All statistical analyses were performed on SPSS 20.0 (SPSS Inc., Chicago, Illinois, USA).

\section{Results}

Table 1 shows that the rs 1801173 of $p 73$ was located in the first chromosome. Their category was protein cod. The minor allele frequency of rs 1801173 in the controls was 0.267 . The result of HWE tests for the controls was $0.229(P>0.05)$, indicating that the sample population was representative. The snapshot method was used for genotyping, and the percentage of successful tests was $98.96 \%$.

Table 1

Primary information for $p 73$ rs 1801173 gene polymorphism

\begin{tabular}{|c|c|c|c|c|c|c|c|c|}
\hline $\begin{array}{l}\text { Genotyped } \\
\text { SNP }\end{array}$ & Gene & $\begin{array}{l}\text { Chr Pos } \\
\text { (NCBI } \\
\text { Build 38) }\end{array}$ & Category & $\begin{array}{l}\text { MAFa for } \\
\text { Chinese } \\
\text { in } \\
\text { database }\end{array}$ & $\begin{array}{l}\text { MAF in } \\
\text { our } \\
\text { controls } \\
(n= \\
678)\end{array}$ & $\begin{array}{l}\text { P value } \\
\text { for } \\
\text { HWE }^{b} \\
\text { test in } \\
\text { our } \\
\text { controls }\end{array}$ & $\begin{array}{l}\text { Genotyping } \\
\text { method }\end{array}$ & $\begin{array}{l}\text { Genotypi } \\
\text { value (\%) }\end{array}$ \\
\hline rs1801173 & $p 73$ & $1: 3682346$ & 5_prime_UTR_variant,genic_upstream_transcript_variant & 0.267 & 0.229 & 0.821 & snapshot & 98.96 \\
\hline
\end{tabular}

Table 2 shows that the cases including demographics and environmental risk factors. Smoking rate was much higher in case group as compared with the control group (34.49\% vs. $27.29 \%, P=0.006)$. The demographics (age and sex) were well matched $(P=0.635$ and $P=0.698$, respectively; Table 2 ). That indicated the occurrence and development of smoking and gastric cancer. Of the alcohol consumption, no significant difference was observed between $\mathrm{GC}$ patients and controls $(P=0.443$, Table 2$)$. 
Table 2

Distribution of selected demographic variables and risk factors in GC cases and controls

\begin{tabular}{|llll|}
\hline & Overall Cases $(\mathbf{n}=\mathbf{5 7 7})$ & Overall Controls $(\mathbf{n = 6 7 8 )}$ & $\boldsymbol{P}$ \\
\hline Age (years) & $\mathbf{n}(\%)$ & $\mathbf{n}(\%)$ & 0.065 \\
\hline Age (years) & $61.34 \pm 11.097$ & $62.31 \pm 7.549$ & \\
\hline$<62$ & $268(46.45)$ & $324(47.79)$ & 0.635 \\
$\geq 62$ & $309(53.55)$ & $354(52.21)$ & 0.698 \\
\hline Sex & & & \\
\hline Male & $394(68.28)$ & $456(67.26)$ & 0.006 \\
\hline Female & $183(31.72)$ & $222(32.74)$ & \\
\hline Smoking status & & & 0.443 \\
\hline Never & $378(65.51)$ & $493(72.71)$ & \\
\hline Ever & $199(34.49)$ & $185(27.29)$ & \\
\hline Alcohol use & & $520(76.70)$ & \\
\hline Never & $453(78.51)$ & $158(23.30)$ & \\
\hline Ever & $124(21.49)$ & & \\
\hline
\end{tabular}

Table 3 The frequency distribution and logistic regression analysis of the $p 73$ gene rs 1801173 polymorphism in gastric cancer and control group showed that with reference to wild-type CC, the frequency distribution of TC heterozygous mutations in GC cases was $60.67 \%$ higher than 59.55 in controls group, but there was not statistically significant between the two groups $(P=0.657)$ and there was no statistical difference in gender, age, smoking, and alcohol consumption after logistic regression adjustment $(P=0.691)$; the frequency distribution of TT homozygous mutants was $5.52 \%$ higher than 5.41 in controls group, but was also not statistically significant $(P=1.000)$, and there was no statistical difference after logistic regression adjustment $(P=0.979)$. In the dominant model, the frequency distribution of TC + TT mutations was $39.33 \%$ lower than $40.45 \%$ in controls group, but there was not statistically significant in the case-control group $(P=0.688)$, and the difference was not statistically significant after regression adjustment $(P=0.703)$. In the recessive model, the frequency distribution was $5.52 \%$ higher than 5.41 in controls group, but there was not statistically different $(P=0.937)$. According to gender, age, smoking, and drinking, after logistic regression analysis, there was still no statistical difference between the two groups $(P=0.990)$. The results of rs1801173 allele frequency distribution of $p 73$ gene in the two groups showed that the allelic frequency distribution was not statistically significant in the case-control group $(P=0.763)$.

Table 3

p73 rs1801173 gene polymorphisms in GC cases and controls and logistic regression analysis

\begin{tabular}{|c|c|c|c|c|c|c|c|c|}
\hline \multirow[t]{2}{*}{ Genotype } & \multicolumn{2}{|c|}{$\begin{array}{l}\text { GC Cases } \\
(n=577)\end{array}$} & \multicolumn{2}{|c|}{$\begin{array}{l}\text { Controls } \\
(n=678)\end{array}$} & \multirow[t]{2}{*}{$\begin{array}{l}\text { Crude OR } \\
(95 \% \mathrm{Cl})\end{array}$} & \multirow[t]{2}{*}{$P$} & \multirow[t]{2}{*}{$\begin{array}{l}\text { Adjusted OR }{ }^{a} \\
(95 \% \mathrm{Cl})\end{array}$} & \multirow[t]{2}{*}{$P$} \\
\hline & $\mathbf{n}$ & $\%$ & $\mathrm{n}$ & $\%$ & & & & \\
\hline \multicolumn{9}{|l|}{ rs1801173 } \\
\hline $\mathrm{CC}$ & 341 & 60.67 & 396 & 59.55 & 1.00 & & 1.00 & \\
\hline $\mathrm{TC}$ & 190 & 33.81 & 233 & 35.04 & $0.95(0.75-1.20)$ & 0.657 & $0.95(0.75-1.21)$ & 0.691 \\
\hline TT & 31 & 5.52 & 36 & 5.41 & $1.00(0.61-1.65)$ & 1.000 & $1.00(0.77-1.28)$ & 0.979 \\
\hline $\mathrm{TC}+\mathrm{TT}$ & 221 & 39.33 & 269 & 40.45 & $0.95(0.76-1.20)$ & 0.688 & $0.98(0.81-1.00)$ & 0.703 \\
\hline $\mathrm{CC}+\mathrm{TC}$ & 531 & 94.48 & 629 & 94.59 & 1.00 & & 1.00 & \\
\hline TT & 31 & 5.52 & 36 & 5.41 & $0.98(0.60-1.61)$ & 0.937 & $1.00(0.78-1.29)$ & 0.990 \\
\hline C allele & 872 & 77.58 & 1025 & 77.07 & 1.00 & & 1.00 & \\
\hline T allele & 252 & 22.42 & 305 & 22.93 & $0.97(0.80-1.17)$ & 0.763 & & \\
\hline
\end{tabular}

Stratification was conducted in accordance with four longitudinal factors, namely, sex, age, smoking, and drinking, to observe the influence of various genotypes and genetic patterns and diseases and calculate the frequency distribution of the case-control group.Table 4 shows that regardless of the gender, the distribution frequency of the four modes, namely, mutant, wild-type, recessive model, and dominant model, had no difference in the distribution of the two groups, suggesting that gender and $p 73$. No statistical correlation was found between the four genetic models and the occurrence of GC. Age, smoking, drinking, and temporarily also showed no statistical association. However, a notable detail that in Table 1, a statistically significant difference was found in the association between smoking and the occurrence of GC. In the hierarchical analysis, the genetic model of the four genes did not show a statistically 
significant association, which is worthy of follow-up study to investigate and determine whether smoking factors are related to the rs 1801173 polymorphisms of $p 73$.

Table 4

Stratified analyses between $p 73$ rs 1801173 gene polymorphisms and risk by sex, age, smoking and drinking

\begin{tabular}{|c|c|c|c|c|c|c|c|c|}
\hline \multirow[t]{2}{*}{ Variable } & \multicolumn{3}{|c|}{ (case/control) } & \multicolumn{5}{|c|}{ Adjusted OR (95\% Cl); $P$} \\
\hline & $\mathrm{CC}$ & $\mathrm{TC}$ & TT & $\mathrm{CC}$ & TC & TT & $(\mathrm{TC}+\mathrm{TT}) \mathrm{VSCC}$ & TTVS(CC+TC) \\
\hline \multicolumn{9}{|l|}{ Sex } \\
\hline \multirow[t]{2}{*}{ Male } & $229 / 253$ & $131 / 168$ & $22 / 23$ & 1.00 & 0.86(0.65-1.15); & 1.06(0.57-1.95); & 0.89(0.67-1.17); & $0.89(0.49-1.63)$ \\
\hline & & & & & P:0.314 & P:0.859 & P:0.389 & P:0.715 \\
\hline \multirow[t]{2}{*}{ Female } & $112 / 143$ & $59 / 65$ & $9 / 13$ & 1.00 & 1.16(0.75-1.78); & $0.88(0.37-2.14)$ & 1.11(0.74-1.68); & $0.84(0.35-2.02)$ \\
\hline & & & & & P.0.502 & P.0.785 & P:0.607 & $P .0 .700$ \\
\hline \multicolumn{9}{|l|}{ Age } \\
\hline \multirow[t]{2}{*}{$<62$} & $163 / 182$ & $90 / 117$ & $8 / 16$ & 1.00 & $0.86(0.61-1.22)$ & $0.56(0.23-1.34)$ & $0.82(0.59-1.15)$ & 1.69(0.71-4.02); \\
\hline & & & & & $P: 0.390$ & $P .0 .186$ & $P: 0.255$ & $P: 0.228$ \\
\hline \multirow[t]{2}{*}{$\geq 62$} & $178 / 214$ & $100 / 116$ & $23 / 20$ & 1.00 & 1.04(0.74-1.45); & 1.38(1.74-2.60); & 1.09(0.79-1.49); & $0.73(0.39-1.36)$ \\
\hline & & & & & P.0.833 & P.0.313 & P.0.602 & $P .0 .324$ \\
\hline \multicolumn{9}{|l|}{ Smoking } \\
\hline \multirow[t]{2}{*}{ Never } & $228 / 290$ & $119 / 172$ & $21 / 24$ & 1.00 & $0.87(0.65-1.16)$ & 1.11(0.60-2.05); & 0.91(0.69-1.20) & $0.86(0.47-1.57)$ \\
\hline & & & & & P:0.331 & P.0.731 & P:0.498 & P:0.619 \\
\hline \multirow[t]{2}{*}{ Ever } & $113 / 106$ & $71 / 61$ & $10 / 12$ & 1.00 & 1.09(0.71-1.68); & 0.78(0.32-1.89); & 1.04(0.69-1.57); & 1.32(0.56-3.14); \\
\hline & & & & & P.0.691 & P.0.583 & P:0.849 & $P .0 .526$ \\
\hline \multicolumn{9}{|l|}{ Drinking } \\
\hline \multirow[t]{2}{*}{ Never } & $273 / 305$ & $144 / 180$ & $23 / 28$ & 1.00 & $0.89(0.68-1.18)$ & 0.68(0.39-1.16); & $0.90(0.69-1.17)$ & 1.42(0.83-2.42); \\
\hline & & & & & $P: 0.420$ & P.0.156 & P:0.414 & $P: 0.196$ \\
\hline \multirow[t]{2}{*}{ Ever } & $68 / 91$ & $46 / 53$ & $8 / 8$ & 1.00 & 1.16(0.70-1.92); & 1.34(0.48-3.75); & 1.19(0.73-1.92); & $0.79(0.29-2.17)$ \\
\hline & & & & & $P: 0.561$ & P:0.578 & P:0.491 & $P: 0.650$ \\
\hline
\end{tabular}

\section{Discussion}

GC is a multifactorial disorder, in which genetic and environmental interactions serve an important role in the development and progression ${ }^{[23]}$. Increasing age, gender, lifestyle, dietary regime, environmental factors, and Helicobacter pylori infections are among the known risk factors for stomach cancer ${ }^{[24]}$. While dietary regime and lifestyle are the most recognized factors, enhanced identification of the genetic risk factors is expected to improve the understanding of the basic molecular events involved in tumorigenesis ${ }^{[25]}$. Genetic factors, including gene expression profile and cancer biomarkers, such as SNPs, have a crucial role in improving the early diagnosis of $\mathrm{GC}^{[26]}$.

Recent studies have demonstrated that a high number of genes and various environmental factors are the causal agents of GC, and the presence of different forms of alleles in gene polymorphisms may promote the development of cancers. In this regard, $p 73$ has been a research focus due to its role as a major tumor suppressor gene ${ }^{[27]}$. $p 73$ has some functions similar to or independent of $p 53$ and plays a role, particularly in compensation for loss of $p 53$ function, in the regulation of cell cycle, DNA repair, apoptosis, and possibly cell differentiation. In the past decades, almost 146 unique variations were reported (shown in the Biomuta database) ${ }^{[28]}$, while numerous studies probed into the relationship of G4C14-A4T14 polymorphism and cancer genomics. G4A (rs2273953) and C14T (rs1801173) polymorphisms are located at positions 4 ( $G$ to A) and 14 ( $C$ to $T$ ) of exon 25'-untranslated region, which may influence the initiating AUG codon by constructing a stem loop ${ }^{[29]}$. In recent years, the G4C14-A4T14 polymorphism of $p 73$ has been identified to be implicated in the tumorigenesis of various cancer types. However, the data from these published case-control studies were not consistent.

Yang et al. ${ }^{[30]}$ and Niwa et al. ${ }^{[31]}$ reported that G4C14-A4T14 polymorphism is not associated with the susceptibility of cervical cancer in Uighur and Japanese population, respectively. However, Craveiro et al. ${ }^{[32]}$ and Feng et al. ${ }^{[33]}$ revealed that G4C14-A4T14 polymorphism leads to an increasing risk of cervical cancer. Hamajima et al. ${ }^{[34]}$ demonstrated no significant differences in the genotype frequencies among the enrolled cases and controls in their study of colorectal cancer. On the contrary, Lee et al. ${ }^{[35]}$ reported that GC/AT and AT/AT genotypes are significantly associated with the risk of colorectal cancer in Korean population. Arfaoui et al. ${ }^{[36]}$ also uncovered no remarkable differences in genotype frequencies in cancers and controls, but they found that AT/AT genotype may cause poor prognosis of colorectal cancer. Hu et al. ${ }^{\left[{ }^{[3]}\right]}$ indicated that AT/AT and GC/AT variants are associated with a remarkable decrease in the risk of 
lung cancer. Li et al. ${ }^{[38]}$ suggested that the AT/AT and GC/AT genotypes are related, with a statistically significantly increased risk of lung cancer. However, Choi et al. ${ }^{[39]}$ revealed that the G4C14-A4T14 polymorphism of $p 73$ does not affect the susceptibility of lung cancer in Korean population. Zheng et al. ${ }^{[9]}$ found that the rs $1801173 \mathrm{C}>\mathrm{T}$ SNPs of $p 73$ are associated with increased risk of ESCC. However, $p 73$ gene polymorphism and GC susceptibility have not been reported yet. Therefore, the rs $1801173 \mathrm{C} / \mathrm{T}$ polymorphism of $p 73$ merits further functional study to elucidate the etiology of SNP and GC.

In the present study, no statistically significant association was found between $p 73 \mathrm{rs} 1801173 \mathrm{C}>\mathrm{T}$ gene polymorphism and the risk of $\mathrm{GC}$ in a Chinese Han Population. Although the $\mathrm{C}$ mutant allele frequency was higher in patients with GC than in controls, the difference was not statistically significant. However, the frequency of smoking factors in the case group was $34.49 \%$, higher than that in the control group by $27.29 \%$, and the difference was statistically significant. This result showed that smoking is related to the occurrence and development of GC. Li et al. ${ }^{[40]}$ studied the connection between $p 73 \mathrm{G} 4 \mathrm{C} 14$-toA4T14 polymorphism and the risk of lung cancer. They found that the increased risk associated with the combined $p 73 \mathrm{GC} / \mathrm{AT}+\mathrm{AT} / \mathrm{AT}$ genotype in younger ( $\leq 50$ years) subjects and light (compared with heavy) smokers suggested an early onset and lower levels of exposure characteristic of genetic susceptibility. They also observed a significantly higher risk in men than in women, particularly among smokers. However, the interaction between smoking and $p 73$ polymorphism was only borderline significant, which warrants additional investigations with larger sample sizes.

This case-control study had several limitations. First, because the patients and controls were enrolled from hospitals, inherent bias may have resulted in spurious findings. Second, the polymorphisms may not provide a comprehensive view of $p 73$ genetic variability. Fine-mapping studies are required. Third, the statistical power was limited because of the moderate sample size and the absence of a validation cohort. In addition, considering that gene-gene interaction and gene-environment interaction play an important role in the pathogenesis of many diseases, especially chronic diseases, $p 73$ gene polymorphism may interact with other gene polymorphisms or environmental factors, thereby affecting the incidence of GC in the population. H. pylori infections, lifestyle, and dietary regime were not investigated. Other limitations included small sample size and sampling of individuals of the same geographical region and race. Therefore, further studies considering different geographical locations and races and a larger number of participants are necessary to confirm the results of the present study. These results failed to indicate an association between $p 73$ rs 1801173 polymorphism and risk of GC. Tissue-specific biological characterization and replication studies with larger populations are also required to confirm these findings.

\section{Declarations}

\section{Data Availability}

The data used to support the findings of this study are available from the corresponding authors upon request.

\section{Ethical Approval}

The research was approved by the Ethics Review Committee of Jiangsu University.

\section{Consent}

All patients provided written informed consent.

\section{Conflicts of Interest}

The authors declare that they have no conflflicts of interest.

\section{Authors' Contributions}

Xuyu Gu is the co-fifirst author. Xiaoyan Wang and Xuyu Gu wrote and edited the manuscript. Yu Fan, Guowen Ding, and Zhenjun Gao provided direction and guidance throughout the preparation of this manuscript. Huiwen Pan finished the data analysis. All authors read and approved the final manuscript.

\section{Acknowledgments}

This study was supported in part by Jiangsu Provincial Key Research and Development Special Fund (BE2015666), Jiangsu Innovative team leading talent fund (CXTDC2016006), Jiangsu six high peak talent fund (WSW-205), Jiangsu 333 talent fund(BRA2020016) and Suqian science and technology support project fund (S201721).In addition, the authors thank all participants of this study.

\section{References}

1. Bray F. Ferlay J, Soerjomataram I. Siegel RL, Torre LA. Jemal A. Global cancer statistics 2018: GLOBOCAN estimates of incidence and mortality worldwide for 36 cancers in 185 countries [published correction appears in CA Cancer J Clin. 2020 Jul;70(4):313]. CA Cancer J Clin. 2018;68(6):394-424.

doi:10.3322/caac. 21492 . 
2. Wang FH. Shen L, Li J, et al. The Chinese Society of Clinical Oncology (CSCO): clinical guidelines for the diagnosis and treatment of gastric cancer. Cancer Commun (Lond). 2019;39(1):10. Published 2019 Mar 18. doi:10.1186/s40880-019-0349-9.

3. Feng W. Ding Y, Zong W. Ju S. Non-coding RNAs in regulating gastric cancer metastasis. Clin Chim Acta. 2019;496:125-33. doi:10.1016/j.cca.2019.07.003.

4. Köberle B. Koch B, Fischer BM. Hartwig A. Single nucleotide polymorphisms in DNA repair genes and putative cancer risk. Arch Toxicol. 2016;90(10):2369-88. doi:10.1007/s00204-016-1771-2.

5. Yan C. Zhu M, Huang T. Yu F, Jin G. Genome-wide association studies identified loci contribute to phenotypic variance of gastric cancer. Gut. 2018;67(7):1366-8.doi:10.1136/gutjnl-2017-315230.

6. Hua RX. Zhuo Z, Zhu J, et al LIG3 gene polymorphisms and risk of gastric cancer in a Southern Chinese population. Gene. 2019;705:90-4. doi:10.1016/j.gene.2019.04.072.

7. He J. Zhuo ZJ, Zhang A, et al Genetic variants in the nucleotide excision repair pathway genes and gastric cancer susceptibility in a southern Chinese population. Cancer Manag Res. 2018;10:765-74. Published 2018 Apr 12. doi:10.2147/CMAR.S160080.

8. He J. Wang MY, Qiu LX, et al Genetic variations of mTORC1 genes and risk of gastric cancer in an Eastern Chinese population. Mol Carcinog. 2013;52 Suppl 1:E70-9. doi:10.1002/mc.22013.

9. Zheng L. Tang W, Shi Y, et al. p21 rs3176352 G > C and p73 rs1801173 C > T polymorphisms are associated with an increased risk of esophageal cancer in a Chinese population. PLoS One. 2014;9(5):e96958. Published 2014 May 12. doi:10.1371/journal.pone.0096958.

10. Liu J. Jin Y, Chen L. Association between p73 gene G4C14-to-A4T14 polymorphism and risk of lung cancer: A meta-analysis. J Pak Med Assoc. 2020;70(2):313-9. doi:10.5455/JPMA.5150.

11. Čechová J. Coufal J, Jagelská EB. Fojta M, Brázda V. p73, like its $p 53$ homolog, shows preference for inverted repeats forming cruciforms. PLoS One. 2018;13(4):e0195835. Published 2018 Apr 18. doi:10.1371/journal.pone.0195835.

12. Yi Y. Zhang W, Yi J. Xiao ZX. Role of p53 Family Proteins in Metformin Anti-Cancer Activities. J Cancer. 2019;10(11):2434-42. Published 2019 May 27. doi:10.7150/jca.30659.

13. Liu Y. Dong W, Mou Q. Leng Y, Zhang L. Duan L. Impact of p73 gene polymorphism on cancer susceptibility: a meta analysis. Int J Clin Exp Pathol. 2014;7(10):6820-5. Published 2014 Sep 15.

14. Zhang X. Li X, Wu Z. Lin F, Zhou H. The p73 G4C14-to-A4T14 polymorphism is associated with risk of lung cancer in the Han nationality of North China. Mol Carcinog. 2013;52(5):387-91. doi:10.1002/mc.21869.

15. Hu Y. Jiang L, Zheng J. You Y, Zhou Y. Jiao S. Association between the p73 exon 2 G4C14-to-A4T14 polymorphism and cancer risk: a meta-analysis. DNA Cell Biol. 2012;31(2):230-7. doi:10.1089/dna.2011.1305.

16. Deng B. Liu F, Wei Y, et al Association of a p73 exon 2 G4C14-to-A4T14 polymorphism with risk of hepatocellular carcinoma in a Chinese population. Tumour Biol. 2013;34(1):293-9. doi:10.1007/s13277-012-0550-9.

17. Umar M. Upadhyay R, Khurana R. Kumar S, Ghoshal UC. Mittal B. Role of p53 and p73 genes polymorphisms in susceptibility to esophageal cancer: a case control study in a northern Indian population. Mol Biol Rep. 2012;39(2):1153-62. doi:10.1007/s11033-011-0844-9.

18. Lööf J. Pfeifer D, Adell G. Sun XF. Significance of an exon 2 G4C14-to-A4T14 polymorphism in the p73 gene on survival in rectal cancer patients with or without preoperative radiotherapy. Radiother Oncol. 2009;92(2):215-20. doi:10.1016/j.radonc.2009.06.007.

19. avakkol Afshari Z. Gholizadeh Z, Nikpoor AR, et al A Case-Control Study on the p73 G4A Gene Polymorphism and Susceptibility to Breast Cancer in an Iranian Population. Iran J Public Health. 2019;48(10):1855-60.

20. Li W. Wang SS, Deng J. Tang JX. Association of p73 gene G4C14-A4T14 polymorphism and MDM2 gene SNP309 with non-small cell lung cancer risk in a Chinese population. Oncol Lett. 2017;14(2):1817-22. doi:10.3892/ol.2017.6327.

21. Guo H. Yang S, Xu L, et al Association between the p73 gene G4C14-to-A4T14 single nucleotide polymorphism and risk of cervical cancer by high resolution melting and PCR with confronting two-pair primers in a Chinese population. Oncol Lett. 2016;12(1):721-6. doi:10.3892/ol.2016.4655.

22. Ding GW. Gu XY, Dai Z, et al Association of Genetic Polymorphisms in FOXA1 with the Progression of Genetic Susceptibility to Gastric Cancer. Gastroenterol Res Pract. 2020;2020:3075837. Published 2020 Jan 27. doi:10.1155/2020/3075837.

23. Zhang Z. Yin J, Xu Q. Shi J. Association between the XPG gene rs2094258 polymorphism and risk of gastric cancer. J Clin Lab Anal. $2018 ; 32(8): e 22564$. doi:10.1002/jcla.22564.

24. Eybpoosh S. Talebkhan Y, Saberi S, et al Age-Specific Gastric Cancer Risk Indicated by the Combination of Helicobacter pylori Sero-Status and Serum Pepsinogen Levels. Iran Biomed J. 2015;19(3):133-42. doi:10.7508/ibj.2015.03.002.

25. Huang Q. Unique Clinicopathology of Proximal Gastric Carcinoma: A Critical Review. Gastrointest Tumors. 2014;1(3):115-22. 10.1159/000365305. doi.

26. Nabatchian F. Rahimi Naiini M, Moradi A, et al miR-581-Related Single Nucleotide Polymorphism, rs2641726, Located in MUC4 Gene, is Associated with Gastric Cancer Incidence. Indian J Clin Biochem. 2019;34(3):347-51. doi:10.1007/s12291-018-0751-0.

27. Kotulak A. Wronska A, Kobiela J. Godlewski J, Stanislawowski M. Wierzbicki P. Decreased expression of p73 in colorectal cancer. Folia Histochem Cytobiol. 2016;54(3):166-70. doi:10.5603/FHC.a2016.0018.

28. Dingerdissen HM. Torcivia-Rodriguez J, Hu Y. Chang TC, Mazumder R. Kahsay R. BioMuta and BioXpress: mutation and expression knowledgebases for cancer biomarker discovery. Nucleic Acids Res. 2018;46(D1):D1128-36. doi:10.1093/nar/gkx907.

29. Meng J. Wang S, Zhang M. Fan S, Zhang L. Liang C. TP73 G4C14-A4T14polymorphism and cancer susceptibility: evidence from 36 case-control studies. Biosci Rep. 2018;38(6):BSR20181452. Published 2018 Dec 14. doi:10.1042/BSR20181452. 
30. Yang Z. Nie S, Zhu H, et al Association of p53 Arg72Pro polymorphism with bladder cancer: a meta-analysis. Gene. 2013;512(2):408-13. doi:10.1016/j.gene.2012.09.085.

31. Niwa Y. Hamajima N, Atsuta Y, et al Genetic polymorphisms of p73 G4C14-to-A4T14 at exon 2 and p53 Arg72Pro and the risk of cervical cancer in Japanese. Cancer Lett. 2004;205(1):55-60. doi:10.1016/j.canlet.2003.11.014.

32. Craveiro R. Bravo I, Catarino R, et al The role of p73 G4C14-to-A4T14 polymorphism in the susceptibility to cervical cancer. DNA Cell Biol. 2012;31(2):2249. doi:10.1089/dna.2011.1294.

33. Feng H. Sui L, Du M. Wang Q. Meta-analysis of TP73 polymorphism and cervical cancer. Genet Mol Res. 2017;16(1):10.4238/gmr16016571. Published 2017 Jan 23. doi:10.4238/gmr16016571.

34. Hamajima N. Matsuo K, Suzuki T, et al No associations of p73 G4C14-to-A4T14 at exon 2 and p53 Arg72Pro polymorphisms with the risk of digestive tract cancers in Japanese. Cancer Lett. 2002;181(1):81-5. doi:10.1016/s0304-3835(02)00041-1.

35. Lee KE. Hong YS, Kim BG, et al p73 G4C14 to A4T14 polymorphism is associated with colorectal cancer risk and survival. World J Gastroenterol. 2010;16(35):4448-54. doi:10.3748/wjg.v16.i35.4448.

36. Arfaoui AT. Ben Mahmoud LK, Ben Hmida A, et al Relationship between p73 polymorphism and the immunohistochemical profile of the full-length (TAp73) and NH2-truncated ( $\triangle$ Np73) isoforms in Tunisian patients. Appl Immunohistochem Mol Morphol. 2010;18(6):546-54. doi:10.1097/PAl.0b013e3181e9fe58.

37. Hu Z. Miao X, Ma H, et al Dinucleotide polymorphism of p73 gene is associated with a reduced risk of lung cancer in a Chinese population. Int $\mathrm{J}$ Cancer. 2005;114(3):455-60. doi:10.1002/ijc.20746.

38. Li G. Sturgis EM, Wang LE, et al Association of a p73 exon 2 G4C14-to-A4T14 polymorphism with risk of squamous cell carcinoma of the head and neck. Carcinogenesis. 2004;25(10):1911-6. doi:10.1093/carcin/bgh197.

39. Choi JE. Kang HG, Chae MH, et al No association between p73 G4C14-to-A4T14 polymorphism and the risk of lung cancer in a Korean population. Biochem Genet. 2006;44(11-12):543-50. doi:10.1007/s10528-006-9056-8.

40. Li G. Wang LE, Chamberlain RM. Amos Cl, Spitz MR. Wei Q. p73 G4C14-to-A4T14 polymorphism and risk of lung cancer. Cancer Res. 2004;64(19):68636. doi:10.1158/0008-5472.CAN-04-1804. 